\title{
Cardiac bypass surgery with haemorrhagic endocrine sequelae
}

\author{
Romesh Khardori, Robert C. Bussing, George M. Burns and Norman G. Soler. \\ Department of Internal Medicine, Southern Illinois University School of Medicine, Springfield, Illinois, USA.
}

\begin{abstract}
Summary: Cardiac bypass surgery is associated with changes in haemostatis which can lead to bleeding. This report highlights two examples of such bleeding which led to unusual clinical presentations and endocrinological consequences: adrenal and pituitary haemorrhage.
\end{abstract}

\section{Introduction}

Cardiac bypass surgery is an increasingly common procedure which differs from other types of surgery since it involves extracorporeal circulation, induction of hypothermia and use of large amounts of heparin. The endocrine responses to the stress of coronary bypass are also strikingly different from the responses to other surgery. ${ }^{1}$ In addition, cardiac bypass surgery is associated with unique haemostatic changes: they range from consumptive coagulopathy to platelet damage, haemodilution, thrombocytopenia, factor $\mathbf{V}$ deficiency, loss of fibrinogen receptors from platelets, loss of platelet $\alpha_{2}$-adrenergic receptors, heparin excess and heparin rebound..$^{2-7}$

In this report we describe two patients who, following cardiac bypass surgery, developed adrenal haemorrhage and pituitary apoplexy.

\section{Case reports}

\section{Case 1}

A 42 year old white male, with severe stenosis of the left coronary anterior descending artery, underwent a left internal mammary artery bypass without any intraoperative complications. Routine investigations before surgery were normal and his perioperative and early postoperative course was uneventful. On the 4th postoperative day, he developed fever (temperature $38.3^{\circ} \mathrm{C}$ ) and on the 6th postoperative day abdominal pain radiating to the left flank accompanied by diarrhoea. A day later (7th postoperative day) he became confused and disorientated with total loss of recent memory and was noted to have a systolic BP of $100 \mathrm{~mm} \mathrm{Hg}$ supine without any postural hypotension.

Correspondence: Norman G. Soler, M.D. Department of Medicine, SIU School of Medicine, P.O. Box 3926, Springfield, IL 62708, USA

Accepted: 16 December 1986
By the 10th postoperative day the patient became more symptomatic with orthostatic hypotension. He remained febrile and a search for a source of infection was unrewarding. The patient also developed hyponatraemia $\left(\mathrm{Na}^{+} / \mathrm{K}^{+}: 129 / 4.3 \mathrm{mmol} / \mathrm{l}\right)$, and by the 15 th postoperative day the serum sodium was $125 \mathrm{mmol} / 1$ with potassium levels beginning to rise $\left(\mathrm{K}^{+}: 5.1 \mathrm{mmol} / 1\right.$ on the 15 th day and $5.6 \mathrm{mmol} / \mathrm{l}$ on the 16 th day). At $08.00 \mathrm{~h}$ his plasma cortisol was $71.7 \mathrm{nmol} / 1$ (normal $138-552 \mathrm{nmol} / 1$, and ACTH $132.4 \mathrm{pmol} / 1$ (normal 1$27.5 \mathrm{pmol} / \mathrm{l}$ ). A diagnosis of primary adrenal insufficiency was made which was corroborated by an ACTH stimulation test during which the peak cortisol level was only $135.2 \mathrm{nmol} / \mathrm{l}$. Computerized tomography (CT) of the abdomen revealed an enlarged left adrenal gland which was compatible with adrenal haemorrhage into this gland (Figure 1). Once the patient was started on steroid replacement therapy there was quick resolution of the fever, clearing of the confusional state and correction of orthostatic hypotension.

A follow-up CT scan of the abdomen (16 months postoperatively) shows a return of the adrenal gland to normal size without any masses, suggesting that the patient had suffered an adrenal haemorrhage which had resolved.

\section{Case 2}

A 62 year old male with angiographically documented multivessel coronary artery disease underwent aortocoronary bypass surgery. Physical examination and routine preoperative investigations were normal.

His surgery was conducted without any intraoperative complications. However, 8 hours after surgery he developed a temperature $\left(38.2^{\circ} \mathrm{C}\right)$, and on the second postoperative day right-sided ptosis and dilatation of the pupil became apparent. Neurological examination indicated complete paralysis of the 3rd, 4th and 6th cranial nerves on the right side with 


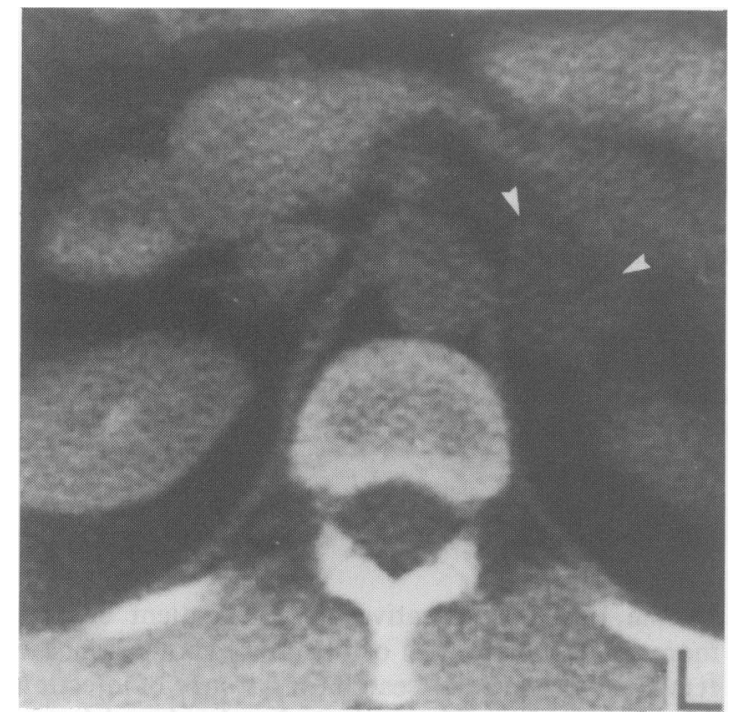

Figure 1 Computed tomographic scan of the upper abdomen. An enhancing lesion is seen in the left adrenal region.

resultant internal and external ophthalmoplegia. A left homonymous hemianopia was also demonstrable and the patient complained of mild weakness of the left side of the body. Clinically there was no evidence of motor weakness or sensory deficit. The plantar responses were flexor. A CT scan of the head showed normal ventricles and no evidence of intracerebral haemorrhage or other significant pathology.

The patient remained febrile and by the 11th postoperative day he became incoherent. His temperature rose to $40^{\circ} \mathrm{C}$ and was associated with rigors. At this stage a repeat CT scan of the head demonstrated an enhancing lesion in the region of the pituitary fossa with a mild mass effect on the anterior aspect of the supra sellar cistern. With contrast there was a ring enhancement in this region (Figure 2), suggesting an intrasellar mass, most likely representing haemorrhage into the pituitary. This intrasellar location was confirmed on carotid angiography

Blood samples were obtained for endocrine studies and the patient was started on intravenous hydrocortisone. After the first dose of hydrocortisone the patient became afebrile (temperature $37^{\circ} \mathrm{C}$ ) for the first time in 12 days. Over the following days his sensorium cleared and he became coherent. Once the diagnosis of pituitary apoplexy was established, evacuation of the sella was recommended. A transsphenoidal approach was employed and frankly haemorrhagic and necrotic tissue obtained. The microscopic examination showed haemorrhagic infarction of a pituitary adenoma.

Postoperatively the patient was afebrile, his visual

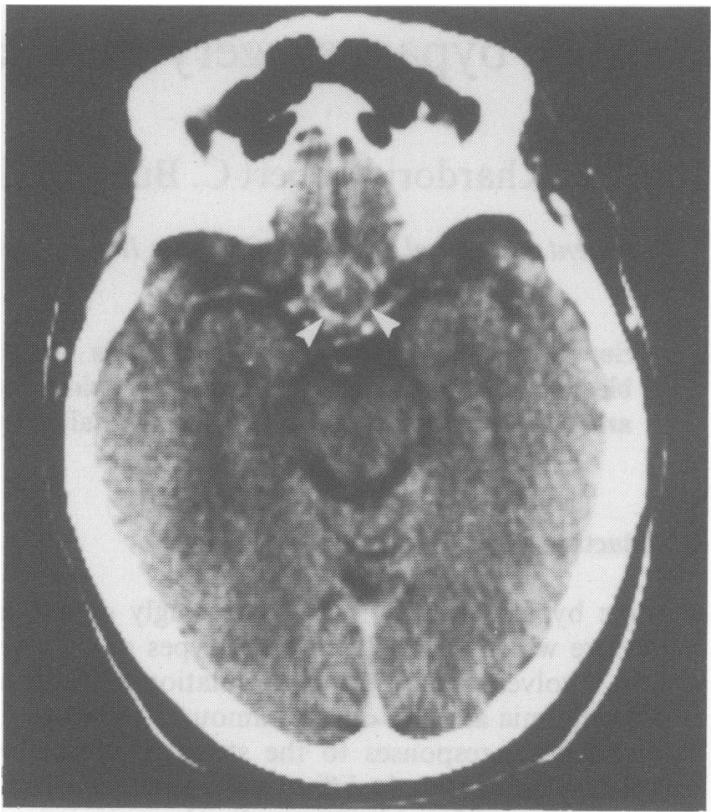

Figure 2 Computed tomographic scan of the head showing an enhancing lesion with ring-like appearance in the sellar region.

field defect resolved and there was improvement subjectively in the left sided weakness. The patient was discharged from hospital on corticosteroid and thyroid hormone replacement.

\section{Discussion}

In this report two patients who did not have obvious disturbances of haemostasis or thrombocytopenia following cardiac bypass surgery sustained haemorrhage into the adrenal and pituitary glands. A diagnosis of adrenal haemorrhage was delayed in the first case until orthostatic hypotension and hyponatraemia supervened. In this regard the report by Xarli et al. ${ }^{8}$ is instructive. In a series of 22 patients with adrenal haemorrhage they found that hyponatraemia (defined as $\mathrm{Na}^{+}$under $135 \mathrm{mmol} / \mathrm{l}$ ) affected $36 \%$ of patients, hyperkalaemia $\left(\mathrm{K}^{+}\right.$over $\left.5.4 \mathrm{mmol} / \mathrm{l}\right) 14 \%$, and systolic hypotension (BP under $90 \mathrm{mmHg}$ ) $63 \%$. Therefore reliance on electrolyte changes and hypotension alone can be misleading. In our patient CT scanning of the abdomen aided considerably in the diagnosis. There are only occasional reports ${ }^{9}$ of the use of computed tomography for the diagnosis of adrenal haemorrhage although CT has been extensively used in the diagnostic of adrenal tumours. ${ }^{10}$ Our patient demonstrated unilateral involvement, which is rather unusual. In most of the reported studies of adrenal haemorrhage 
bilateral exceeds unilateral involvement." However, there are other reports documenting unilateral adrenal haemorrhage..$^{12-16}$ The adrenal crisis would be difficult to explain on the basis of unilateral haemorrhage, and we believe that in our patient the other gland must have also been involved. In one previous study from a major medical centre 5 out of 4,364 adult patients undergoing cardiac bypass surgery developed acute adrenal insufficiency. ${ }^{17}$ Exposure to anticoagulants and other factors including stress, high ACTH levels and venous thrombosis may be involved in the aetiology of acute adrenal haemorrhage. ${ }^{18-20}$ Although adrenal haemorrhage can occur following noncardiac surgery, ${ }^{11}$ the patients undergoing coronary bypass surgery may be at increased risk because of use of large amounts of anticoagulant (heparin) intraoperatively. Adrenal haemorrhage is nowadays the second leading cause of primary adrenal insufficiency. ${ }^{21}$

The patient with pituitary apoplexy was unusual in lacking headache which is a most common symptom, occurring in about $63 \%$ of cases; ${ }^{22}$ he also lacked nuchal rigidity and symptoms of raised intracranial pressure. His clinical presentation included fever and hemiparesis, rare features of pituitary apoplexy. ${ }^{22}$ This

\section{References}

1. Taylor, K.M., Jones, V.J., Walker, M.S., Rao, S. \& Bain, W.H. The cortisol response during heart lung bypass. Circulation 1976, 54: 20-25.

2. Blombeck, M., Noren, I. \& Senning, A. Coagulation disturbances during extracorporeal circulation and the postoperative period. Acta Chir Scand 1964, 127: 433445.

3. Gralnick, H.R. \& Fischer, R.D. The hemostatic response to open heart operations. J. Thorac Cardiovasc Surg 1971, 61: 909-915.

4. Edmunds Jr., L.H., Ellison, N., Colman, R.W. et al. Platelet function during cardiac operation: Comparison of bubble oxygenators. J Thorac Cardiovasc Surg 1982, 83: 805-812.

5. Sobel, M. \& Salzman, E.W. Hemorrhagic and thrombotic complications of cardiac surgery. In Glen, W.W.L. (ed) Thoracic and Cardiovascular Surgery. AppletonCentury Crofts, Norwalk, Connecticut, 1983, pp. 12631275.

6. Musial, J., Niewiarowski, S., Hershock, D., Colman, R.W. \& Edmunds Jr., L.H. Loss of fibrinogen receptors from the platelet surface during simulated extracorporeal circulation. J Lab Clin Med 1985, 105: $514-522$.

7. Wachtfogel, Y.T., Musial, J., Niewiaroswki, S., Edmunds Jr., L.H. \& Colman R.W. Loss of platelet $\alpha_{2}$ adrenergic receptors during simulated extracorporeal circulation: Prevention with prostaglandin $\mathrm{E}_{1} . J$ Lab Clin Med 1985, 105: 601-607.

8. Xarli, V.P., Steele, A.A., Davis, P.J., Buescher, E.S., Rios, C.N. \& Garcia-Bunuel, R. Adrenal hemorrhage in the adult. Medicine (Baltimore) 1978, 57: 211-221. patient may have been predisposed to pituitary haemorrhage because of his undiagnosed pituitary adenoma. Pituitary adenomas appear to have a propensity for haemorrhage ${ }^{23}$ possibly because of their increased vascularity. ${ }^{24}$ In the present case, low levels of growth hormone and prolactin favour a nonfunctioning tumour corroborated by lack of thyroid stimulating hormone response to thyrotropin-releasing hormone. No attempts were made to perform additional provocative tests such as a combined test since such a procedure could potentially aggravate the pituitary apoplexy. ${ }^{25,26}$ Computed tomography, as in the first case, strongly aided the diagnosis although it is of interest that the first CT was negative. The hormone levels recorded and the prompt response to corticosteroid therapy strengthened the diagnosis.

In summary, the cases we are reporting have a common message: that during coronary bypass surgery haemostatic mechanisms are altered and that bleeding may therefore result. Although frank bleeding may occur, occasionally subtle symptoms may be the only indication of haemorrhage. A correct diagnosis may be lifesaving as in the cases of adrenal and pituitary haemorrhage included in this report.

9. Wheatley, T., Gallagher, S. \& Dixon, A.K. Adrenal insufficiency and bilateral adrenal enlargement: Demonstration by computed tomography. Postgrad Med J 1985, 61: 435-438.

10. Albert, S.G., Wolverson, M.K. \& Johnson, F.E. Bilateral adrenal hemorrhage in an adult: Demonstration by computed tomography. JAMA 1982, 247: 17331739.

11. Clark, O.H. Postoperative adrenal hemorrhage. Ann Surg 1975, 182: 124-128.

12. Galin, M.A. Unilateral adrenal hemorrhage during ACTH therapy. $N$ Engl J Med 1958, 258: 945-946.

13. Fox, B. Unilateral adrenal necrosis and hemorrhage following operations on the stomach. J Pathol 1969, 97: 127-135.

14. Miller, A. Adrenal apoplexy, report of two cases. Proc $R$ Soc Med 1960, 53: 345-348.

15. Castleman, B. \& McNeely, B.U. Case records of Massachusetts General Hospital. N Engl J Med 1969, 280: 772 776.

16. Moore, M.A. \& Biggs, P.J. Unilateral adrenal hemorrhage: An unusual presentation. South Med J 1985, 78: 989-992.

17. Alford, W.C., Meador, C.K., Hihalevich, J. et al. Acute adrenal insufficiency following cardiac surgical procedures. J Thorac Cardiovasc Surg 1979, 78: 489493.

18. Wilbur, O.M. \& Rich, A.R. A study of the role of adrenocorticotrophic hormone (ACTH) in the pathogenesis of tubular degeneration of the adrenals. Bull Johns Hopkins Hosp 1953, 93: 321-335.

19. Proctor, E.L. \& Rawson, A.J. Adrenal cortical failure 
following treatment with cortisone and ACTH. Am J Clin Path 1951, 21: 158-162.

20. Berte, S.J. Spontaneous adrenal hemorrhage in the adult: Literature review and report of two cases. Ann Intern Med 1953, 38: 28-37.

21. Anderson, K.C., Kuhajda, F.P. \& Bell, W.R. Diagnosis and treatment of anticoagulant related adrenal hemorrhage. Am J Hematol 1981, 11: 379-385.

22. Wakai, S., Fukushima, T., Teramato, A. \& Sano, K. Pituitary apoplexic incidence and clinical significance. $J$. Neurorsurg 1981, 55: 187-193.
23. Hickstein, D.D., Chandler, W.F. \& Marshall, J.C. The spectrum of pituitary adenoma hemorrhage. West $J$ Med 1986, 144: 433-436.

24. Jefferson, G. Extrasellar extension of pituitary adenomas. Proc R Soc Med 1940, 33: 433-458.

25. Bernstein, M., Hegele, R.A., Gentili, F. et al. Pituitary apoplexy associated with a triple bolus test. $J$ Neurosurg 1984, 61: 586-590.

26. Chapman, A.J., Williams, G., Hockley, A.D. \& London, D.R. Pituitary apoplexy after combined test of anterior pituitary function. $\mathrm{Br} \mathrm{Med} J$ 1985, 291: 26. 